\title{
Fisiopatología de la retinopatía y nefropatía diabéticas
}

\author{
Pablo 0 Imos $^{1}$, Andrea Araya-Del-Pinoa , Cristián Gonzáleza, \\ Pablo Laso ${ }^{a}$, Verónica Irribarra ${ }^{1}$, Lorena Rubio ${ }^{b}$. \\ Pathophysiology of diabetic \\ retinopathy and nephropathy
}

\begin{abstract}
Despite the availability of multiple therapeutic approaches, diabetes mellitus with chronic hyperglycemia remains as the main cause of new cases of blindness and chronic renal failure in the western hemisphere. We herein review the molecular mechanisms by which chronic hyperglycemia causes retinopathy and nephropathy in type I and type 2 diabetic patients. Diabetic retinopathy develops silently along years or decades, producing symptoms only in its very late stages. Its slow development starts with the activation of aldose reductase, shortly followed by the destruction of the retinal pericyte cells, and ends in sudden blindness when vitreous hemorrhage ensues. Nephropathy, on the other hand, centers its pathophysiology in the mesangial cell, that starts as a modified smooth-muscle cell, and turns itself into a myo-fibroblast, produces such amounts of cytoplasm and extracellular protein that strangulates the glomerular capillaries and causes renal failure. After a detailed review of the molecular mechanisms of the aforementioned complications, we conclude that, apart from directing our attention to the emerging medications that are being developed to block these molecular pathways, we should never abandon the struggle for improving the glycemic control of our diabetic patients (Rev Méd Chile 2009; 137: 1375-84).
\end{abstract}

(Key words: Diabetes mellitus; Diabetic nephropathy; Diabetic retinopathy)

Recibido el 1 de septiembre, 2008. Aceptado el 7 de enero, 2009.

${ }^{1}$ Departamento de Nutrición, Diabetes y Metabolismo, Facultad de Medicina, Pontificia Universidad Católica de Chile. Santiago de Chile

anternos de Medicina, Pontificia Universidad Católica de Chile

bioquímica, Pontificia Universidad Católica de Chile

\begin{abstract}
A 1 despuntar el siglo 21, se desencadenó la "Epidemia Global de Diabetes", un fenómeno relacionado particularmente con la diabetes mellitus tipo 2 (no-insulinodependiente), y que está teniendo lugar tanto en países desarrollados como en desarrollo ${ }^{1}$. En consecuencia, se estima que la
\end{abstract}

$\overline{\text { Correspondencia a: Dr. Pablo R. Olmos. Departamento de Nu- }}$ trición, Diabetes y Metabolismo, Facultad de Medicina, Pontificia Universidad Católica de Chile. Alameda 340, Santiago 6513492. Fonos: 3543863, 3543862. E mail: polmos@med.puc.cl prevalencia mundial de diabetes tipo 2 aumente desde los 171 millones que había en el año 2000, a una cifra de al menos 366 millones el año $2030^{2}$. A pesar que en la actualidad disponemos de una gran variedad de herramientas de tratamiento efectivas para la diabetes tipo 2, las así llamadas "complicaciones microvasculares" (retinopatía y nefropatía) son responsables directas de la morbilidad más frecuente asociada a la diabetes tipo 2 . En efecto, en el hemisferio occidental, la retinopatía diabética es la causa más común de nuevos casos de ceguera en adultos en edad de trabajar 
(20-74 años), y la nefropatía diabética es la causa individual más frecuente de insuficiencia renal terminal ${ }^{3}$.

En los pocos años de este siglo, han ocurrido importantes avances en la fisiopatología de las complicaciones microvasculares de la diabetes. Como estos avances están ya teniendo impacto en las metas de control metabólico y en el desarrollo de nuevos medicamentos, resulta de capital importancia que médicos de todas las especialidades estén familiarizados con los mecanismos patogénicos que detallaremos a continuación.

\section{Fenómeno universal: GLicosilación De proteínAs}

El año 1912, Maillard fue el primero en reportar la formación de substancias de color marrón por la reacción no-enzimática entre azúcares y aminoácidos. Maillard denominó "melanoidinas" a los productos finales, los que adquirieron gran importancia en la industria alimentaria, ya que se ha llegado a demostrar que estas melanoidinas constituyen un componente esencial de los colores, olores, sabores y texturas de muchas comidas, incluyendo el conocido "manjar blanco" (dulce de leche) ${ }^{4}$. Esta "reacción de Maillard" (sinónimo de glicosilación) no sólo ocurre en nuestras cocinas, sino que, como demostraron en 1981 Monnier y Cerami ${ }^{5}$, también tiene lugar en el cuerpo humano, donde después de décadas llevan a la síntesis de proteínas irreversiblemente glicosiladas similares a las melanoidinas, denominadas "Productos de Glicosilación Avanzada" (AGE, por sus siglas en inglés).

En la actualidad se sabe que los AGE se forman en personas diabéticas (y en mucho menor medida en no diabéticas con la edad avanzada) en presencia de hiperglicemia crónica, y pueden acumularse en proteínas de larga vida, como en el cristalino del ojo, en el colágeno de las membranas basales de los capilares retinales y glomerulares, y también en el componente proteico de la mielina en el sistema nervioso periférico.

La Figura 1 muestra que la glicosilación de proteínas puede dividirse en tres fases: iniciación, propagación y AGE.

La iniciación va desde la formación de la base de Schiff hasta el producto Amadori. En esta fase, la glucosa reacciona con los residuos epsilón- ámino $\left(-\mathrm{NH}^{+}\right)$del aminoácido lisina, que asoman sobre la superficie de toda proteína. Se forma una base de Schiff, que es un conjugado de glucosa y proteína. Si la hiperglicemia persiste, en el curso de horas ésta se transforma en un "Producto Amadori", que es más estable. Un ejemplo de producto Amadori es la hemoglobina glicosilada, donde la glucosa se combina con la globina, que es el componente proteico de la hemoglobina del glóbulo rojo ${ }^{6}$. Dependiendo de si la hiperglicemia que lo causó se corrige o no, el

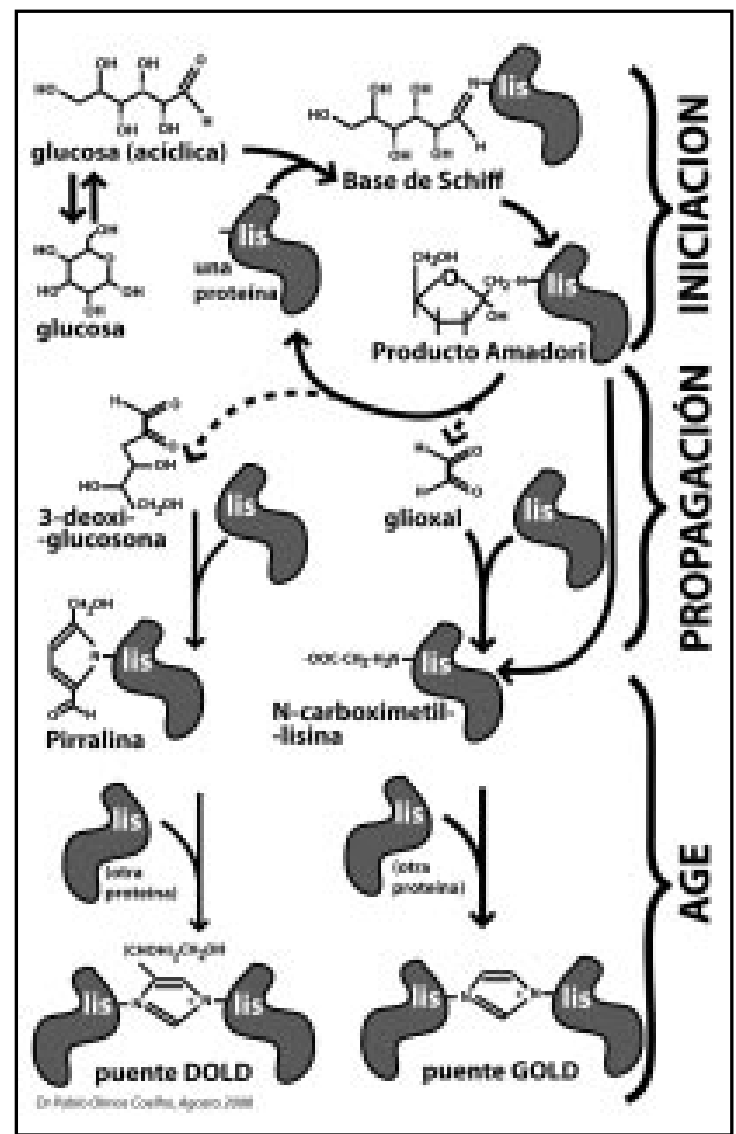

Figura 1. Glicosilación no enzimática de proteínas en el ser humano vivo, con sus tres fases: iniciación, propagación y AGE (Producto de Glicosilación Avanzada). Las moléculas con forma de silla y color gris oscuro representan proteínas de larga vida, y el acrónimo "lis" en su interior representa un aminoácido en particular-la lisina, cuyos residuos epsilonámino $\left(-\mathrm{NH}^{+}\right)$son particularmente susceptibles de glicosilación (ver texto). 
producto Amadori tiene dos destinos. Si la glicemia se normaliza, entonces éste se desglicosila, desprendiendo una molécula de proteína sin daño alguno. Sin embargo, la glucosa desprendida del producto Amadori no vuelve a ser glucosa, sino que se transforma en radicales libres violentamente oxidantes ${ }^{7}$ (ver más adelante). En segundo lugar, si la hiperglicemia que generó el producto Amadori persistiera por años, entonces éste no se desglicosilaría, sino que sufriría nuevas reacciones oxidantes que veremos en la siguiente fase.

La fase de propagación parte con la formación de los dicarbonilos oxidantes (observe que no van unidos a una proteína) glioxal y de 3-deoxiglucosona, que son producto de la desglicosilación de parte del producto Amadori, y que son potentes agentes glicantes, capaces de catalizar nuevas reacciones de unión de glucosa a proteínas. En esta fase ocurren varias reacciones de glicooxidación proteica, todas ellas tendientes a formar productos de glicosilación que, como están unidos a una sola proteína, no forman puente entre dos de ellas (pirralina y N-carboximetil-lisina). Observe que la N-carboximetil-lisina puede formarse tanto a partir de la combinación de glioxal con proteína, como a partir de la acción oxidativa del glioxal y otros radicales libres sobre el producto Amadori que ha persistido de la fase anterior ${ }^{7}$.

La fase de AGE comienza -insistimos, en presencia de hiperglicemia persistente por años- precisamente con la unión de la pirralina y de la N-carboximetillisina con una segunda proteína, formando "AGE nofluorescentes pero que forman puente", llamados "puente DOLD" y "puente GOLD". Al formarse estos puentes, se alteran irreversiblemente las estructuras terciaria y cuaternaria de las proteínas ${ }^{7-9}$.

Los puentes DOLD y GOLD no son los únicos AGE que se forman luego de décadas de hiperglicemia. También se generan AGE que forman puentes entre la lisina de una proteína con la arginina de otra. Entre ellos están "puente Glucosespano" y el "puente Pentosidina". Este último es además fluorescente, ya que emite luz visible al ser iluminado con luz ultravioleta.

¿Cuál es el destino de los AGEs en las personas diabéticas? En el cristalino del ojo, las proteínas glicosiladas contribuyen a su opacificación y a la formación de cataratas ${ }^{4}$. En los nervios periféricos, la glicosilación del componente proteico de la mielina hace a ésta apetecible para ser fagocitada por macrófagos que tienen receptores de AGE (RAGE) $)^{10,11}$, contribuyendo así a la génesis de la neuropatía diabética. Respecto a lo que sucede en la retina del ojo y en el glomérulo del riñón, lo veremos en las dos secciones siguientes con más detalle, ya que en éstas no sólo influye la glicosilación proteica, sino que también otras vías metabólicas.

\section{LA RETINOPATÍA DIABÉTICA}

La Figura 2 muestra la secuencia de eventos en la retinopatía diabética. Se observa un capilar retinal que, emergiendo desde una arteriola, cruza la figura desde izquierda a derecha, recostado sobre un lecho de fibras nerviosas. En la histología de la retinopatía, lo primero que sucede es la muerte de

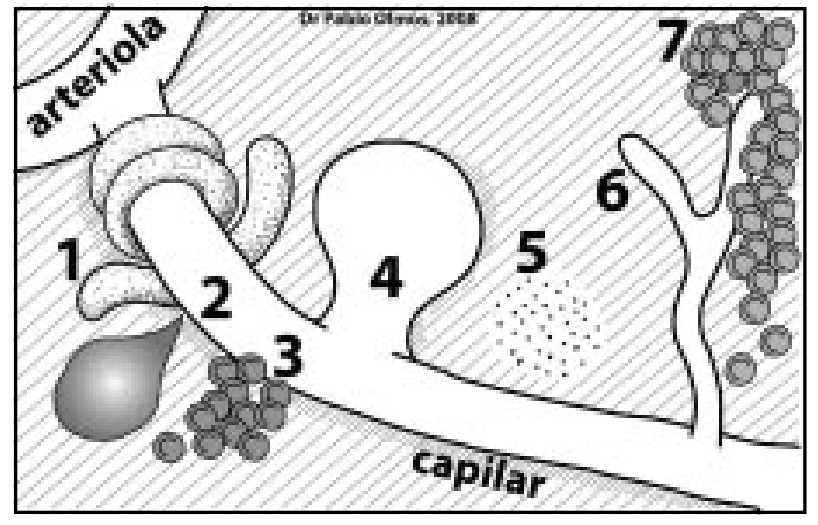

Figura 2. Retinopatía diabética. Secuencia de eventos a nivel del capilar retinal. A la izquierda de la figura, donde desde la arteriola emerge el vaso capilar, puede observarse dos pericitos envolviendo a éste último, lo que es la situación normal. 1 =pericito en fase de destrucción mientras se desprende del vaso capilar. 2 ="exudado céreo". 3 =microhemorragia. 4 =microaneurisma. 5 = "exudado algodonoso". 6 =vaso de neoformación. 7 =hemorragia vítrea. Los tamaños son aproximados. El diámetro de un eritrocito es de 7 micrometros. Las líneas paralelas en el plano de fondo corresponden a la capa de fibras nerviosas de la retina (ver texto). 
los pericitos, que son células nodrizas, que normalmente rodean a los capilares retinales. Posteriormente, la pared capilar, cuya membrana basal se ha glicosilado, aumenta su permeabilidad, permitiendo la salida de plasma rico en lipoproteínas, formándose gotitas de color amarillo brillante, visibles en el examen de fondo de ojo como "exudados céreos", ya que tienen el aspecto de gotitas de cera derretida. Aunque estos exudados céreos pueden ser asintomáticos y sólo visibles con el oftalmoscopio, a veces pueden hacer disminuir la agudeza visual si es que están cerca de la mácula. Posteriormente, la pared capilar debilitada por la pérdida de pericitos puede agrietarse y producir "microhemorragias", las que no causan síntomas porque no afectan a la mácula, que carece de capilares. El debilitamiento de la pared capilar puede llegar al extremo de causar dilataciones llamadas "microaneurismas". Aunque éstos tampoco comprometen la agudeza visual, en su interior pueden formarse microtrombos, con la consiguiente oclusión capilar e isquemia retinal. Al sumarse esta última con otros factores que reducen el flujo capilar (ver más adelante y Figura 3), se producen microinfartos de retina, que aunque son indoloros y asintomáticos, destruyen fibras nerviosas y producen en el examen oftalmoscópico, manchas pálidas de bordes difusos, llamadas "exudados algodonosos". En esta etapa, los tejidos retinales tratan de defenderse de la isquemia, produciendo substancias que estimulan el crecimiento de nuevos capilares (VEGF, ver más adelante). Cuando, efectivamente estos "vasos de neoformación" crecen e invaden silenciosamente el cuerpo vítreo (retinopatía proliferativa), si no son fotocoagulados a tiempo con láser por el oftalmólogo, se rompen, inundan de sangre el cuerpo vítreo, causando ceguera súbita por "hemorragia vítrea".

La Figura 3 muestra la vía de la aldosa reductasa en el vaso capilar y la patogénesis de la retinopatía diabética. Esta vía puede dividirse en dos fases: la fase del pericito y la fase del endotelio.

La fase del pericito: La Figura 3-A muestra que, en presencia de hiperglicemia, la enzima aldosa reductasa (ALR) produce sorbitol a partir de glucosa, y otra enzima, la sorbitol deshidrogenasa,

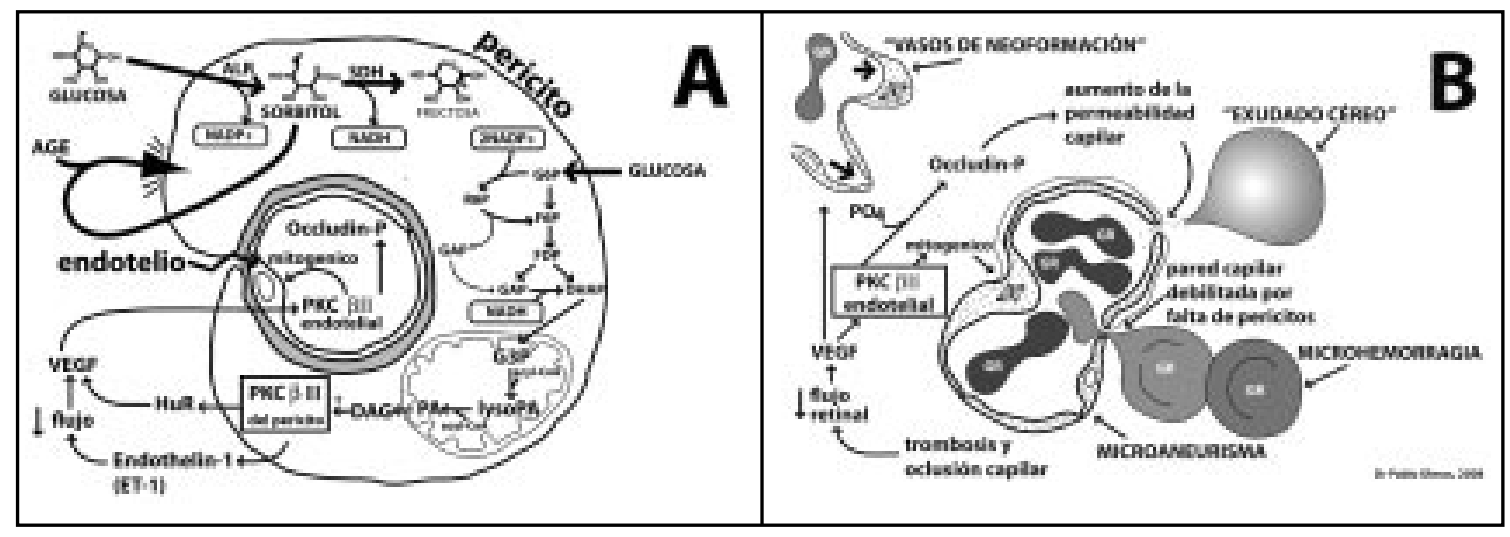

Figura 3. Patogénesis molecular de la retinopatía diabética. (A): Fase del pericito: Esquema de un capilar retinal formado por endotelio y membrana basal, rodeado de un pericito. Esta fase va desde la hiperglicemia, pasa por la activación de la aldosa-reductasa (ALR), hasta llegar a la "etapa de isquemia pericito-dependiente", con producción de VEGF [Vascular Endotelial Growth Factor]. Esta fase termina con la destrucción del pericito. G6P = glucosa-6-fosfato. $\mathrm{R} 5 \mathrm{P}$ =ribulosa-5-fosfato. $\mathrm{F} 6 \mathrm{P}$ =fructosa-6-fosfato. $\mathrm{FDP}$ =fructosa-1,6-difosfato. GAP = gliceraldehído-fosfato. DHAP =di-hidroxi-aceton-fosfato. G3P = gliceraldehido-3-fosfato. LysoPA =ácidoliso-fosfatídico. PA =ácido fosfatídico. HuR =proteína estabilizadora del ARNm (ARN mensajero). PKC $§$ II= proteína-kinasa -C subtipo ß II. AGE =advanced glycosilation endproduct (producto de glicosilación avanzada). GR = glóbulo rojo (ver el texto). (B): Fase del endotelio: Esta va desde la destrucción del pericito hasta la "etapa de isquemia endotelio-dependiente". En esta fase aparecen las lesiones retinales clínicamente detectables, tales como: exudados céreos, microhemorragias, vasos de neoformación y hemorragia vítrea (ver el texto). 
transforma el sorbitol en fructosa. El NADP+ y el $\mathrm{NADH}$ procedentes de estas reacciones, desvían el metabolismo de la glucosa hacia una vía aparte, llamada "síntesis de novo de diacil-glicerol (DAG)". El DAG es un activador natural de la proteínakinasa $C\left(\right.$ PKC- $\left.\beta_{\text {II }}\right)$. Esta última aumenta la expresión de endothelin-1, citoquina que hace diminuir el flujo capilar, causando "isquemia retinal de la fase del pericito". La respuesta del pericito es la producción de factor endotelial de crecimiento vascular (VEGF por sus siglas en inglés) ${ }^{12}$, que es reforzado por la proteína HuR, que estabiliza el ARN mensajero (ARNm) del VEGF ${ }^{13}$. Ahora bien, el VEGF recién producido por el pericito estimula receptores en la célula endotelial subyacente, y justo cuando está comenzando a ejercer sus dos efectos allí (ver más adelante), el pericito muere silenciosamente, destruido por los efectos combinados del sorbitol y de los $\mathrm{AGE}^{14}$.

Fase del endotelio: La Figura 3-B muestra que la occludin, fosforilada en la fase previa, permite la apertura de las uniones intercelulares, con salida de plasma rico en lipoproteínas, generando así los exudados céreos que mencionamos más arriba. La misma Figura 1-B muestra que la mitosis de las células endoteliales (estimulada por la PKC$\beta_{\text {II }}$ de la fase previa), sumada al debilitamiento estructural de la pared capilar (por la muerte de los pericitos) no sólo permite la salida de glóbulos rojos, formando microhemorragias, sino que también la formación de dilataciones revestidas de células endoteliales, los microaneurismas. Con los años, tanto los capilares debilitados como los microaneurismas forman microtrombos, que causan microinfartos de retina (los exudados algodonosos mencionados más arriba), y la resultante "isquemia endotelio-dependiente" genera aún más VEGF, el cual estimula el crecimiento de vasos de neoformación y de paso fosforila más occludin, lo que incrementa la permeabilidad capilar aún más ${ }^{15,16}$. Tal como mencionamos más arriba, los vasos de neoformación son frágiles y causan hemorragia vítrea y ceguera.

En honor a mantener una secuencia lógica de eventos, hemos sacrificado mencionar que durante todos los años (o décadas) en que evoluciona la retinopatía, la glicosilación de las proteínas de la membrana basal capilar juega también un papel importante, ya que al alterarse la estructura terciaria y cuaternaria del colágeno, aumenta la per- meabilidad de ésta a las lipoproteínas y otras proteínas del plasma.

\section{LA NEFROPATÍA DIABÉTICA}

La Figura 4 muestra una típica asa capilar de un glomérulo renal en tres fases-normal, hiperfiltración/microalbuminuria y macroalbuminuria/insuficiencia renal.

Capilar normal: Vea la Figura 4-A. La célula mesangial, montada "a caballo" entre los capilares del asa glomerular, es en realidad una célula muscular lisa modificada. En efecto, cuando ésta se contrae -mediante angiotensina-II actuando en receptores $\mathrm{AT}_{1}$ - tracciona la lámina densa y la lámina rara interna de la membrana basal, reduciendo así el diámetro del capilar, con lo que la resistencia intrarrenal aumenta, y la presión hidrostática disminuye, reduciendo la filtración glomerular ${ }^{17}$. Cuando la angiotensina-II actúa sobre receptores $\mathrm{AT}_{2}$, ocurre relajación de la célula mesangial, con efectos opuestos ${ }^{18}$. Una segunda función de la célula mesangial es sintetizar la matriz mesangial, compuesta de colágeno-IV ${ }^{19}$. Esta matriz es empujada entremedio de las láminas rara interna y externa, formando y renovando la lámina densa de la membrana basal glomerular. Finalmente, la célula mesangial degrada la matriz y la lámina densa envejecidas ${ }^{19}$.

Fase de hiperfiltración/microalbuminuria: Ver Figura 4-B. En condiciones de hiperglicemia, disminuye la contractilidad de la célula mesangial, debido a la depolimerización por glicosilación de las fibras de F-actina ${ }^{20}$. El aumento consiguiente del diámetro capilar se suma a la vasoconstricción (dependiente de angiotensina-II) de la arteriola eferente, resultando en hipertensión capilar intraglomerular, la que no sólo explica la hiperfiltración que se ve frecuentemente en los primeros años de diabetes, sino que también produce daño mecánico directo en el glomérulo y un aumento de la permeabilidad de la membrana basal ${ }^{21}$.

En este contexto, en los años recientes se ha acumulado una sólida base de investigación en los mecanismos de microalbuminuria, es decir, en la excreción urinaria de albúmina entre 30 y 299 $\mathrm{mg} / 24 \mathrm{~h}$. Se ha usado a la microalbuminuria como un marcador de nefropatía diabética precoz desde que fue descrita en 1964 por Keen y Viberti ${ }^{22}$. 


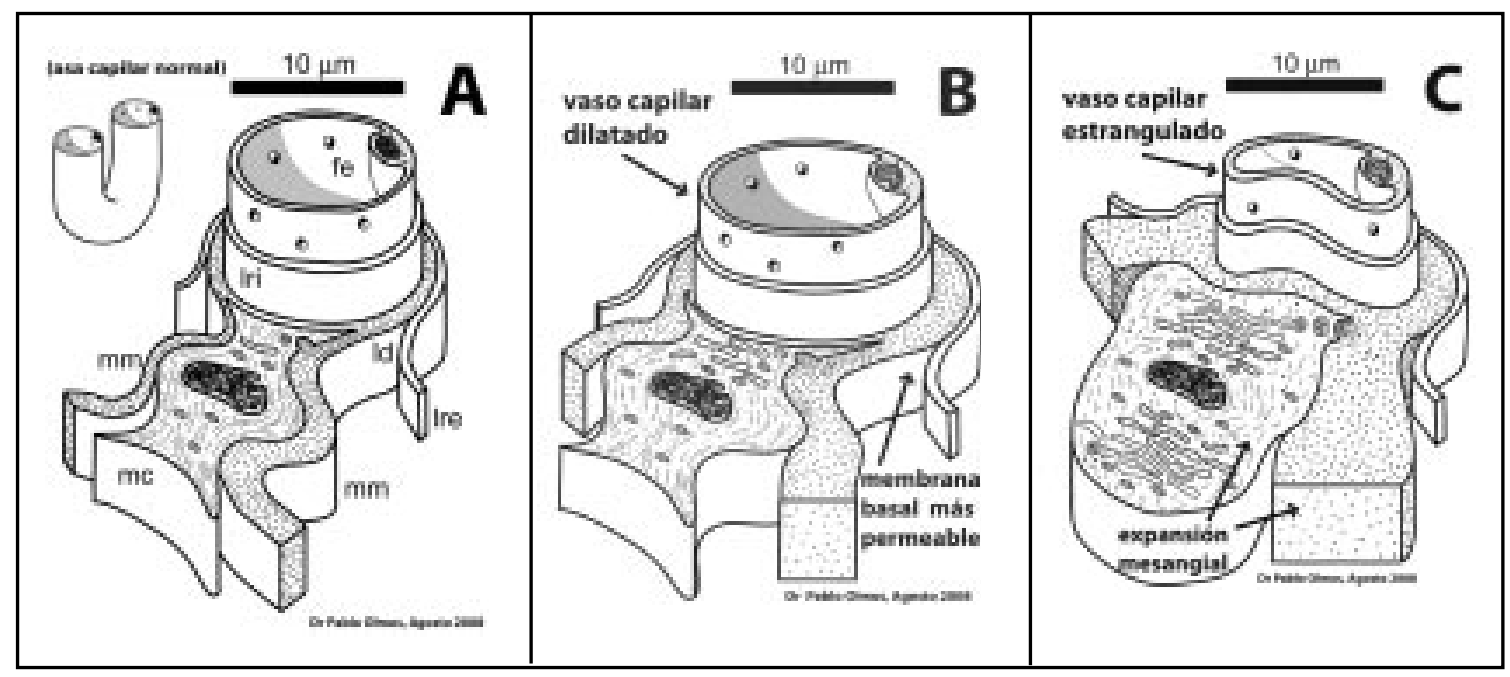

Figura 4. Asa glomerular renal en tres etapas: normal, hiperfiltración-microalbuminuria y macroalbuminuria-insuficiencia renal. (A) Normal: ef =endotelio fenestrado; lre =lámina rara externa; ld =lámina densa; lri =lámina rara interna; $\mathrm{cm}$ =célula mesangial; $\mathrm{mm}=$ matriz mesangial. (B) Hiperfiltración-microalbuminuria: Después de años de hiperglicemia, el vaso capilar glomerular se dilata, debido tanto a la relajación de la célula mesangial, como a la vasoconstricción de la arteriola eferente. Simultáneamente, la membrana basal se hace más permeable a la albúmina (ver el texto). (C) Macroalbuminuria-insuficiencia renal: Después de décadas de hiperglicemia, la suma de la hipertrofia del citoplasma de la célula mesangial, más la acumulación de matriz mesangial, llevan a la "expansión mesangial". El resultado es el progresivo estrangulamiento capilar, que si no se detiene a tiempo, lleva a la insuficiencia renal (ver el texto).

En la misma Figura 4-B ya ha comenzado la acumulación de matriz mesangial y lámina densa (ambos compuestos de colágeno-IV). A pesar de esto, la permeabilidad capilar no sólo no disminuye sino que aumenta debido a la suma de la alta presión hidrostática ya mencionada, más la glicosilación no enzimática del colágeno-IV ${ }^{18}$. Como resultado, comienza la microalbuminuria.

Hasta este momento, se considera que el daño glomerular es reversible, siempre y cuando se corrijan tanto la hiperglicemia como la hipertensión arterial (si es que está presente).

Fase de macroalbuminuria/insuficiencia renal: Si se permite que la hiperglicemia persista por años, entonces, como se ve en la Figura 4-C, la célula mesangial expande su citoplasma mucho más de lo que cabría esperar sólo por la disminución en la contractilidad mencionada arriba. También la matriz mesangial y la lámina densa se acumulan aún más. Tomados en su conjunto, estos cambios constituyen la "expansión mesangial”, que primero elevan la albuminuria por sobre los $300 \mathrm{mg} / 24 \mathrm{~h}$ (macroalbuminuria), y pasando muchas veces por una etapa de síndrome nefrótico, llevan al estrangulamiento capilar y finalmente a la insuficiencia renal. La expansión mesangial se considera como el sello característico de la nefropatía diabética avanzada.

¿Cómo es posible que la hiperglicemia sea tan tóxica para el glomérulo renal?

Ver la Figura 5. En la célula mesangial, una parte significativa del metabolismo de la glucosa se desvía hacia la síntesis de novo de diacilglicerol (DG), que como sabemos es un conocido activador de la proteína-kinasa C (PKC). En el núcleo de esta célula, la PKC (y las MAP-kinasas activadas por ésta) estimulan la expresión de los genes de proteínas de matriz mesangial y también de Transforming Growth Factor Beta (TGF-B). Lo primero contribuye a la acumulación de matriz mesangial ya mencionada. En cambio, el TGF- $\beta$ activa dos proteínas reguladoras (p21 y p27), las que "detienen" el ciclo reproductivo de la célula mesangial en la transición $G_{1} / S$. Se bloquea así la síntesis de ADN, y la célula mesangial duplica una y otra vez su volumen citoplasmático, en prepara- 


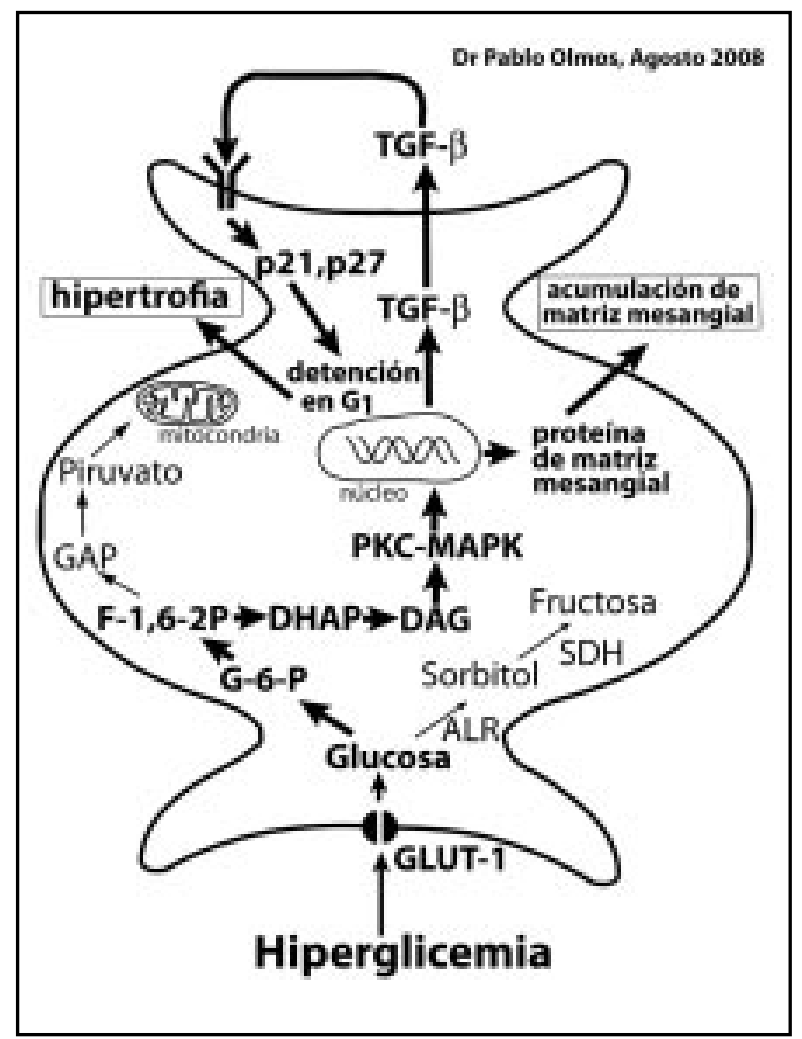

Figura 5. Célula mesangial y los efectos de la hiperglicemia crónica. La glucosa entra libremente a la célula vía el transportador facilitado "Glut-1". Parte de la glucosa sigue la vía de la aldosa reductasa. Pero, una proporción más importante, pasando por glucosa-6-fosfato (G-6$\mathrm{P})$, fructosa 1,6 difosfato (F-1,6-2P) y di-hidroxiaceton-fosfato (DHAP) va a la síntesis de novo de diacil-glicerol (DAG), el cual estimula la proteín-kinasa-C (PKC) y las Map-Kinasas (MAPK). Estas, a su vez, interactúan con los promotores de varios genes del núcleo, lo que tiene dos consecuencias. Por un lado, el aumento en la síntesis de proteína de matriz mesangial, lo que lleva a la acumulación de ésta en el extracelular. Por otro lado, la célula mesangial produce Transforming-Growth-Factor Beta (TGF-B), responsable de desencadenar la síntesis de dos ciclinas P21 y P27 (proteínas reguladoras de ciclo celular). Ambas ciclinas son responsables de la detención del ciclo reproductivo de la célula mesangial en la transición $\mathrm{G}_{1} / \mathrm{S}$, con lo que ésta aumenta su citoplasma sin dividirse, lo que resulta en hipertrofia celular (ver texto). ción para una mitosis que nunca ocurre ${ }^{19,23,24}$. Así entonces, esta hipertrofia celular se suma a la acumulación de matriz mesangial, resultando en la "expansión mesangial" que, si no es detenida a tiempo, termina estrangulando los capilares glomerulares y llevando a la insuficiencia renal.

\section{DisCUSIÓN}

Al comenzar este artículo, teníamos la expectativa de aclarar los mecanismos por los cuales aparecen las complicaciones crónicas de la diabetes mellitus. Hemos llevado gradualmente al lector por el camino de mayor trascendencia, de cómo usar este conocimiento para prevenir y frenar la progresión de la retinopatía y de la nefropatía.

Para ayudarlo en esta tarea, dividiremos las recomendaciones en dos partes, lo que hay que hacer ahora y lo que podríamos hacer en el futuro.
Lo que debemos hacer ahora: Ya en 1996 Ohkubo et $\mathrm{al}^{25}$ (Figura 6), demostró que hay una correlación directa entre la velocidad de empeoramiento de las retinopatía y nefropatía diabéticas, con el mal control glicémico (medido con la hemoglobina glicosilada). Tres años antes, el estudio DCCT ${ }^{26}$ ya había demostrado lo mismo en diabéticos tipo 1.

Por lo tanto, nuestro principal mensaje es que la mejor manera de prevenir la aparición (y frenar la progresión) de las retinopatía y nefropatía diabéticas es luchar porque nuestros pacientes (diabéticos tipo 2 y tipo 1) tengan el mejor control glicémico posible, entendiéndose por tal una hemoglobina glicosilada bajo 7,0 por ciento. También es importante normalizar la presión arterial, ya que ésta puede acelerar la nefropatía (y también la retinopatía) diabéticas.

Lo que podríamos hacer en el futuro: Nuevos enfoques terapéuticos aparecerán en el futuro 


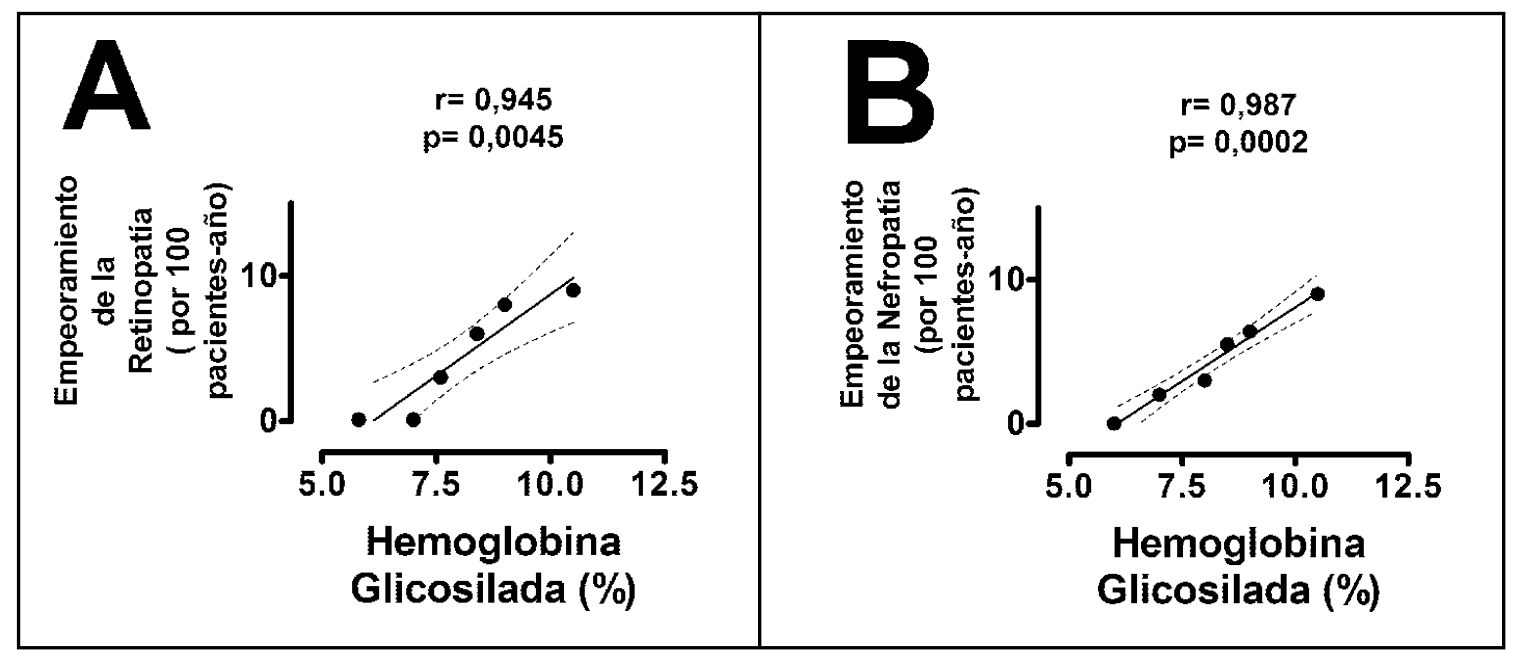

Figura 6. Los gráficos A y B muestran respectivamente, datos de progresión de retinopatía y nefropatía diabéticas y su correlación con control glicémico (hemoglobina glicosilada) obtenidos y re-calculados (no son gráficos publicados) del estudio Kumamoto de diabéticos tipo $2^{25}$. En ambos casos, hay una correlación positiva, altamente significativa, entre el mal control glicémico (mayor hemoglobina glicosilada) y la velocidad de empeoramiento de ambas complicaciones (ver el texto).

próximo, todos ellos orientados a frenar uno o más mecanismos de daño retinal o renal.

A. Medicamentos antiglicosilación. Entre ellos estarían los capturadores de dicarbonilos (aminoguanidina). Otros pueden frenar el paso de producto Amadori a carboximetil-lisina, como la piridoxamina (vitamina B6). Los activadores de la vía de las pentosas (benfotiamina, derivado de la tiamina) desvían la glicólisis hacia la producción de substancias reductoras (NA$\mathrm{DPH})$, que frenarían las reacciones oxidantes en la génesis de AGE. Se están desarrollando "destructores de AGE" (PTB y ALT-711), capaces de romper los puentes anormales AGEproteína. Finalmente, se están desarrollando fármacos "atrapadores de AGE" (RAGE soluble, o sRAGE), que son moléculas similares al receptor de AGE de los macrófagos (RAGE), pero que circulan en forma soluble ${ }^{27}$.

B. Medicamentos anti-PKC. La ruboxistaurina (LY333531) es un inhibidor específico de la PKC- $\beta$ que ha mostrado efectos prometedores en la retinopatía, nefropatía y neuropatía diabéticas tanto en animales como en seres humanos ${ }^{28}$.
C. Bloqueadores de TGF-ß. En animales diabéticos, se están experimentando anticuerpos anti TGF- $\beta$, los que han tenido éxito en prevenir la expansión mesangial y preservar la función renal. En seres humanos, el tratamiento con un inhibidor de la enzima convertidora de angiotensina-II (inhibidor de la ECA), el captopril, es capaz de disminuir la secreción renal de TGF$\mathrm{B}^{27}$. Si estos resultados se confirmaran, resultaría entonces que los medicamentos inhibidores de la ECA tendrían tres efectos renoprotectores en la diabetes: reducirían la presión arterial, la hipertensión glomerular causada por la vasoconstricción de la arteriola eferente, y reducirían la expansión mesangial mediante la reducción en la secreción de TGF-ß.

D. Finalmente, debemos mantenernos atentos a otras líneas de investigación, particularmente en referencia a la nefropatía diabética, donde no sólo la célula mesangial sino otras líneas celulares están atrayendo el interés de los investigadores. El podocito, por ejemplo, que es una célula epitelial modificada, sufre una reducción en su número en los glomérulos afectados por la nefropatía diabética ${ }^{30}$. Por 
otro lado, en la célula endotelial del capilar glomerular, experimentos recientes con ratones transgénicos sugieren que la deficiencia de óxido-nítrico sintetasa endotelial (eNOS, por sus siglas en inglés) y de su producto, el óxido nítrico (NO) pudiesen jugar un papel en la nefropatía diabética ${ }^{31}$.

\section{REFERENCIAS}

1. Zimmet P, Alberti KGMM, Shaw J. Global and societal implications of the diabetes epidemic. Nature 2001; 414: 782-6.

2. Hossain P, Kawar B, El Nahas M. Obesity and diabetes in the developing world. A growing challenge. $\mathrm{N}$ Engl J Med 2007; 356: 213-5.

3. Tong Z, Yang Z, Patel S et al. Promoter polymorphism of the erytropoietin gene in severe diabetic eye and kidney complications. Proc Natl Acad Sci USA 2008; 105: 6998-7003.

4. Sakurai S, Yonekura H, Yamamoto Y, Watanabe T, TANaka N, Li H et al. The AGE-RAGE system and diabetic nephropathy. J Am Soc Nephrol 2003; 14: S259-S263.

5. Monnier VM, Cerami A. Nonenzymatic browning in vivo: Possible process for aging in long-lived proteins. Science 1981; 211: 491-4.

6. Jakus V, Rietbrock N. Advanced glycation endproducts and the progress of diabetic vascular complications. Physiol Res 2004; 53: 131-42.

7. Thornalley PJ, Langborg A, Minhas HS. Formation of glyoxal, methylglyoxal and 3-deoxyglucosone in the glycation of proteins by glucose. Biochem J 1999; 344: 109-16.

8. Ahmed N. Advanced glycation endproducts - role in pathology of diabetic complications. Diab Res Clin Pract 2005; 67: 3-21.

9. Ahmed N, Thornalley PJ. Advanced glycation endproducts: What is their relevance to diabetic complications? Diab Obes Metab 2007; 9: 233-45.

10. Stern DM, Yan SD, Yan SF, Schmidt A-M. Receptor for advanced glycation endproducts (RAGE) and the complications of diabetes. Age Res Rev 2002; 1-15.

11. Bastías MJ, Toro L, Olmos P. [Intensified insulin therapy plus antineuritic medication is more effective than antineuritic alone in painful diabetic neuropathy]. Rev Méd Chile 2006; 134: 1507-15.

12. Evcimen ND, King GL. The role of protein kinase C activation and the vascular complications of diabetes. Pharm Res 2007; 55: 498-510.
Mientras tanto, hemos aprendido entonces que, sean cuales fueren los nuevos fármacos anticomplicaciones que aparezcan en el futuro, no debemos descuidar el mecanismo común de las retinopatía y nefropatía diabéticas, que es la hiperglicemia crónica.

13. Amadio M, Scapagnini G, Lupo G, Drago F, Govoni $S$, Pascale A. PKCß/HuR/VEGF: A new molecular cascade in retinal pericytes for the regulation of VEGF gene expression. Pharm Res 2008; 57: 60-6.

14. Hammes H-P, Lin J, Renner O, Shani M, Lundevist A, Betsholtz C et al. Pericytes and the pathogenesis of diabetic retinopathy. Diabetes 2002; 51: 3107-12.

15. Rask-Madsen C, Zhineng H, King GL. Mechanisms of diabetic microvascular complications. En: Kahn CR, King GL, Moses AC, Weir GC, Jacobson AM, Smith RJ, editores. Joslin's Diabetes Mellitus, $14^{\text {th }}$ edition. Lippincott Williams \& Wilkins, 2005, Philadelphia, Penn, USA. p. 823-7.

16. Harhaj NS, Felinski EA, Wolpert EB, Sundstrom JM, GARDNER TW, ANTONETti DA. VEGF activation of protein kinase $\mathrm{C}$ stimulates occluding phosphorilation and contributes to endothelial permeability. Invest Ophth Vis Sci 2006; 47: 5106-15.

17. ScholdorfF D. The glomerular mesangial cell: an expanding role for a specialized pericyte. FASEB J 1987; 1: 272-81.

18. Schrijvers BF, Devriese AS, Flybjerg A. From hyperglycemia to diabetic kidney disease: The role of metabolic, hemodynamic, intracellular factors and growth factors/cytokines. Endocrine Rev 2004; 25: 971-1010.

19. MASON RM, WAHAB NA. Extracellular matrix metabolism in diabetic nephropathy. J Am Soc Nephrol 2003; 14: $1358-73$.

20. Cortés P, Méndez M, Riser BL, Guérin CJ, RodríguezBarbero A, Hassett C, Yee J. F-actin fiber distribution in glomerular cells: structural and functional implications. Kidney Int 2000; 58: 2452-61.

21. Fliser D, Wagner K-K, Loos A, Tsikas D, Haller H. Chronic Angiotensin-II receptor blockade reduces (intra)renal vascular resistance in patients with type 2 diabetes. J Am Soc Nephrol 2005; 16: 1135-40.

22. Mogensen CE. Microalbuminuria and hypertension with focus on type 1 and type 2 diabetes. J Int Med 2003; 254: 45-66.

23. Wolf G, ShankLand SJ. P27 Kip 1: The "rosebud" of diabetic nephropathy? J Am Soc Nephrol 2003; 14: 819-22. 
24. GRIFFin S, ShankLand SJ. Not just an inhibitor: A role for P21 beyond the cell cycle - "The truth in rarely pure and never simple". J Am Soc Nephrol 2004; 15: 825-6.

25. Ohkubo Y, Kishikawa H, Araki E, Miyata T, Isami S, Mотоуоsнi S ET AL. Intensive insulin therapy prevents the progression of diabetic microvascular complications in Japanese patients with non-insulin-dependent diabetes mellitus: A randomized prospective 6-year study. Diab Res Clin Pract 1996; 28: 103-17.

26. The DCCT Research Group. The effect of intensive treatment of diabetes on the development and progression of long-term complications in insulindependent diabetes mellitus. The Diabetes Control and Complications Trial Research Group. N Engl J Med 1993; 329: 977-86.
27. Peyroux J, Sternberg M. Advanced glycation endproductos (AGEs): Pharmacological inhibition in diabetes. Pathologie Biologie 2006; 54: 405-19.

28. Haneda M, Koya D, Isono M, KikKawa R. Overview of glucose signaling in mesangial cells in diabetic nephropathy. J Am Soc Nephrol 2003; 14: 1374-82.

29. Setter SM, Campbell RK, Cahoon CJ. Biochemical pathways for microvascular complications of diabetes mellitus. Ann Pharmacother 2003; 37: 1858-66.

30. Shankland SJ. The podocyte's response to injury: Role in proteinuria and glomerulosclerosis. Kidney International 2006; 69: 2131-47.

31. Kanetsuna Y, Takahashi K, Nagata M, Gannon MA, Breyer MD, Harris RC, Takahashi T. Deficiency of endotelial nitric-oxide synthase confers susceptibility to diabetic nephropathy in nephropathy-resistant inbred mice. Am J Pathol 2007; 170: 1473-84. 